\title{
La catástrofe de Cabrerizas (Melilla, 26 de septiembre de 1928)
}

Rosa Maria Montero Madrid

\section{1.-INTRODUCCION}

El hombre, que desde su creación, no ha dejado de evolucionar para hacer su vida más próspera y confortable, se ha visto muchas veces sorprendido a largo de su historia por fatales accidentes que han cambiado el ritmo de su vida.

En septiembre del año 1928, la tranquila vida de los españoles (nos referimos a la vida politica del pueblo español que se encuentra dirigida por el dictador Miguel Primo de Rivera, amparado por el rey de España don Alfonso XIII) se vio ensombrecida por dos sucesos dramáticos que tuvieron dimensiones de auténticas catástrofes nacionales: el incendio del Teatro Novedades de Madrid, ocurrido el día 25, que produjo entre muertos y heridos unas 400 víctimas; y la explosión del Polvorín de Cabrerizas Bajas, en Melilla, un día después, del que tratará este breve estudio realizado en el Archivo Municipal de dicha ciudad, y que tiene como principal soporte el periódico local El Telegrama del Rif y las Actas y Memorias de la Junta Municipal.

\section{2.-LOS HECHOS}

Aproximadamente a las 12,40 de la madrugada del 26 de septiembre de 1928 , cuando la mayoría de los melillenses descansaban tranquilamente en sus hogares, enrojeció el cielo y momentáneamente se dejó oír una formidable explosión que produjo una trepidación tan intensa que la mayor parte de los moradores de las viviendas, las abandonaron, lanzándose a la calle. El momento fue, según leemos en la crónica del diario local El Telegrama del Rif, indescriptible. Lo sucedido superó a cuantos sucesos se habían registrado en esta ciudad.

La confusión aumer tó en los primeros momentos porque a poco de oírse la explosión, cayó sobre la ciudad una lluvia de arena, lo que hizo pensar a muchos de los presentes que se trataba de un aerolito caído sobre la ciudad.

La explosión se produjo en el fuerte de Cabrerizas Bajas, dentro del cual se encontraba el polvorín con un almacén que contenía aproximadamente 20 toneladas de pólvora seca (sin humo). Este fuerte, de torre circular de 12 metros de radio con una superficie de 450 metros cuadrados y un foso de 3,80 metros de ancho por 
3,50 metros de fondo, tenia capacidad para una guarnición de 100 hombres y un aljibe de 54 metros cúbicos. Se construyó entre el 16 de agosto de 1884 y el 30 de junio de 1886.

La explosión fue tan tremenda que no quedó ni el más leve vestigio de cimiento y muro, nada, absolutamente nada.

Guarnecian este fuerte los soldados José Chinchilla Nieto y Dionisio Rodriguez Gómez, pertenecientes a la Comandancia de Artilleria, de los que no se encontraron más que restos.

¿Cómo se produjo la catástrofe? No se ha podido aún dar una causa exacta. La pólvora sin humo, no es en sí un explosivo, pero si esta pólvora se encierra herméticamente la expansión de los gases produce su explosión y el desmoronamiento. El fuerte de Cabrerizas Bajas era, en el momento de la explosión, una gigantesca granada, teniendo como única salida la puerta de acceso al mismo y a ello se debe que los efectos de la explosión se dirigieran hacia la ciudad, ya que hacia este lugar estaba enclavada la puerta.

Aunque no se pueden precisar las causas de la explosión, parece que obedeció a un agente exterior 0 a descuido de los vigilantes, pues los análisis realizados en diferentes muestras de pólvora mostraron que ésta se hallaba en buenas condiciones.

El dictamen de los médicos que practicaron las auptosias a los cadáveres, no ofreció ninguna nota de interés para la posterior solución a una explicación más positiva de la espontánea explosión del polvorin. La mayor parte de los difuntos habian fallecido a consecuencia de fractura producida en bóveda craneana y schok traumático debido a los golpes recibidos por los pesados materiales que llovian del cielo después de la explosión. Se calculó que a una altura aproximada de 500 metros habian llegado a ascender las piedras que componian el fuerte. Esto explica también la cantidad de cadáveres mutilados que se encontraron.

\section{3.-PRINCIPALES TESTIMONIOS DE PESAME Y AYUDA}

La explosión del polvorín, se recuerda en la historia de la ciudad melillense con el nombre de "Catástrofe de Cabrerizas". Tras la catástrofe, todo el pueblo se volcó en la ayuda de los afectados.

El presidente accidental de la Junta Municipal, don Francisco de las Cuevas, en ausencia del titular del cargo don Cándido Lobera Girela, hizo una elocución al vecindario melillense que se publicó el mismo día 26 en El Telegrama del Rif, en la que rogaba al pueblo conservara la serenidad para acudir solícitos a reducir las consecuencias fatales del hecho ocurrido y mitigar el dolor de lo irremediable. También comunicaba en dicha elocución la gran labor de la Casa de Socorro y los hospitales de la ciudad estaban llevando a cabo.

Ofrecia refugio, a los que habian perdido sus modestas moradas, en las esuelas nacionales de Ataque Seco, Barrio del Real, Barrio del General Arizón e Instituto Municipal de Higiene, cuyas cantinas escolares les proporcionoarian alimento, así como los comedores de la Asociación General de Caridad. 
Los testimonios de pesar, fueron encabezados por el telegrama del rey, don Alfonso XIII: "Su majestad el rey dolorosamente impresionado por noticia voladura fuerte Cabrerizas, se interesa muy de veras por suerte heridos y desea dé en su nombre el pésame a las familias de las victimas haciendo saber el interés tan grande que toma en el duelo de la población de Melilla."

Otros testimonios recibidos fueron los telegrafiados por el presidente del Gobierno, don Miguel Primo de Rivera; por el Ministro de la Guerra; por el general superior de las fuerzas militares de Marruecos, por el alto comisario, general Sanjurjo; por el director general de colonias..., y por todas las provincias españolas.

Al dia siguiente de la explosión, la Corporación Municipal se reunió en sesión plenaria para adoptar los acuerdos precisos.

Todos los comercios de la ciudad, obedeciendo acuerdos de la Unión Gremial Mercantil, se adhirieron a la manifestación de duelo del pueblo melillense cerrando las puertas de sus comercios. En la Cámara de Comercio bajo la presidencia del señor Sánz, quedaron reunidos los presidentes de las Cámaras oficiales, entidades particulares y cuantos representaban alguna actividad en la vida de Melilla. La reunión tenía por objeto la adopción de acuerdos relacionados con la desgracia que afligia a la ciudad, por unanimidad se aceptaron los siguientes acuerdos:

$\left.1 .^{\circ}\right)$ Testimoniar la más profunda gratitud a todas las autoridades, ejército y elementos de la poblaciónde Melilla por el proceder heróico y humanitario que observaron en el rápido auxilio de las víctimas de la catástrofe.

$2^{\circ}$ ) Abrir una suscripción de carácter público para remediar en lo posible el desamparo en que quedaron los moradores de las viviendas destruidas.

3. ) Solicitar del gobierno de su majestad una determinada cantidad para el mismo fin.

4..$\left.^{\circ}\right)$ Pedir al poder público el inmediato traslado de los polvorines existentes en las inmediaciones de la ciudad.

5.') Que los vapores de la ciudad pertenecientes a las compañías navieras que conducian pasaje, no admitieran explosivos en sus bodegas.

6..$^{\circ}$ Recabar de la Junta Municipal la autorización para la emisión de un empréstito con destino a la construcción de casas baratas.

7..$^{\circ}$ Recabar de los bancos de crédito que tenían sucursales en la ciudad, dieran las mayores facilidades para atenuar en lo posible el trastorno comercial originado por la catástrofe.

$\left.8^{\circ}\right) \mathrm{El}$ entierro oficial de las víctimas sería costeado por la Junta Municipal.

También en la capital de España, se reunieron, el mismo día 27, antes de marchar para Melilla, el alto comisario, general Sanjurjo y el presidente de la Junta Municipal, don Cándido Lobera, con el jefe de gobierno, general Primo de Rivera. Se convino en esta conferencia adoptar las medidas oportunas para evitar la repetición del suceso que había consternado al pueblo de Melilla:

1.9) Se procedería a la retirada de polvorines y reconstrucción del barrio de Cabrerizas.

2.9) Se acordó poner a disposición de las autoridades de Melilla la cantidad de 
50.000 pesetas para atender a lo damnificados, y, que la Junta Municipal fuese la encargada del sepelio de las victimas y adquiriera una parcela en el cementerio de la Purisima Concepción, para la inhumación de los restos de las mismas.

\section{4.-CONCESION DE DONATIVOS}

El Gobierno de la Nación para remediar la situación de las víctimas del Teatro Novedades y Polvorín de Cabrerizas, en una nota oficiosa hizo el siguiente llamamiento a la caridad del pueblo español:

"Con diferencia solo de horas, se han producido en España dos grandes catástrofes en Madrid y Melilla, casi iguales en su espantosa magnitud y aunque los reyes y el Gobierno, los dos ayuntamientos y algunos particulares han acudido caritativos y diligentes al inmediato socorro de las familias que sufren dolores y daños, es preciso además el esfuerzo general ciudadano.

Asi pues, es preciso, sin que el Gobierno eluda el cumplimiento de sus obligaciones en cuanto a reparación de los edificios oficiales y reposición del material perdido, reunir un millón de pesetas o más para llevar a cabo los deberes que se derivan del ser humano caritativo.

En todo caso, deben ser los ayuntamientos respectivos los que organicen, recauden y distribuyan las suscripciones y a ellos deberán enviarse lo más pronto posible por las entidades y personas que quieran aportar su óbolo a esta obra, las cantidades que desean donar.

El Gobierno está seguro que la prensa contribuirá a la publicidad con gran eficacia, exaltando los sentimientos y respondiendo asi las suscripciones que se inicien a un buen resultado."

En la Junta Municipal se recibieron entre otros los siguientes ofrecimientos:

1. ${ }^{\circ}$ ) Presidente del Club Deportivo Español ofrece festival deportivo a beneficio de los damnificados.

2.) Empresario del Teatro Alfonso XIII, señor Suárez, ofrece una función benéfica.

3. ${ }^{\circ} \mathrm{El}$ actor, señor Portes, ofrece los ingresos de la primera función en esta plaza, a beneficio de las víctimas.

4..$^{\circ}$ ) Orfeón melillense, ofrece dar la profesión oficial de piano a dos niños o niñas que demuestren aptitudes para ello y que hayan quedado huérfanos a causa de la catástrofe, abonándoles la matrícula y libros necesarios.

5. ) Capellán de las Escuelas del Ave María se ofrece para celebrar un funeral en dicha capilla.

6.) Don Joaquín López, director de la Academia Hispana, ofrece sus servicios y colegio a los niños que asisten a las escuelas nacionales de Triana y del Barrio del General Arizón.

7.') La Panificadora Valenciana ha cedido 100 kilogramos de pan para la beneficencia. 
8. $^{\circ}$ ) Don José Maria Rey Delgado, apoderado de la sucursal en Melilla de los depósitos de carbones de Ceuta, envió 500 pesetas.

9. $)$ El coronel jefe de Estado Mayor de las fuerzas militares de Marruecos señor Aranda, recibió un telegrama del general jefe de la circunscripción de Ceuta y Tetuán, don José Millán Astray en el que le comunicaba: "Por acuerdo de todos los cuerpos, armas y servicios de la circunscripción, todos los jefes, oficiales y clase de tropa de segunda categoria dejarán un dia de haber para engrosar suscripción iniciada para socorrer a los damnificados a consecuencia de la voladura del fuerte de Cabrerizas Bajas."

10.') El Ayuntamiento de Málaga dando una prueba de amor a Melilla, ha acordado que del total de la recaudación que se obtenga para socorrer a las familias de las víctimas de Cabrerizas y Novedades, el 75 por ciento se destine a Melilla y el 25 por ciento restante a lo damnificados de Madrid.

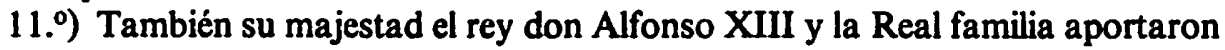
un sustancioso donativo por valor de 10.000 pesetas para las víctimas de la catástrofe de Melilla.

12. ) La reina madre, doña María Cristina contribuyó a la suscripción prodamnificados con la suma de 5.000 pesetas.

Finalmente, la suscripción prodamnificados que se realizó en toda la península y parte del extranjero hasta el 15 de enero de 1929 en que quedó cerrada, aportó en metálico las cantidades que siguen:

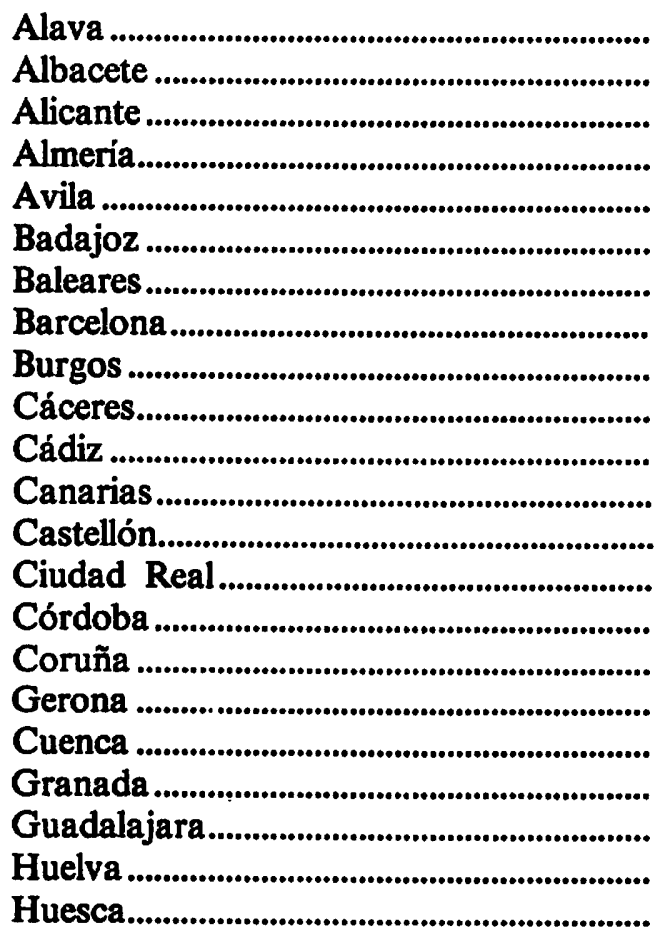

Alava

Albacete

Alicante

Almería

Avila

Badajoz

Baleares.

Burgos

Cáceres.

Castellón

Ciudad Real

Córdoba

Coruña

Gerona

Cuenca

Guadalajara

Huesca
$3.264,65$ pesetas

25,00 pesetas

$3.569,65$ pesetas

$1.271,10$ pesetas

$\mathbf{8 8 8 , 0 0}$ pesetas

2.307,90 pesetas

$2.301,07$ pesetas

$86.888,93$ pesetas

$1.640,15$ pesetas

$1.512,00$ pesetas

863,75 pesetas

150,00 pesetas

38,50 pesetas

150,00 pesetas

$8.498,70$ pesetas

$2.454,70$ pesetas

$1.750,70$ pesetas

400.00 pesetas

$2.112,25$ pesetas

0,00 pesetas

$1.429,50$ pesetas

$5.135,00$ pesetas 


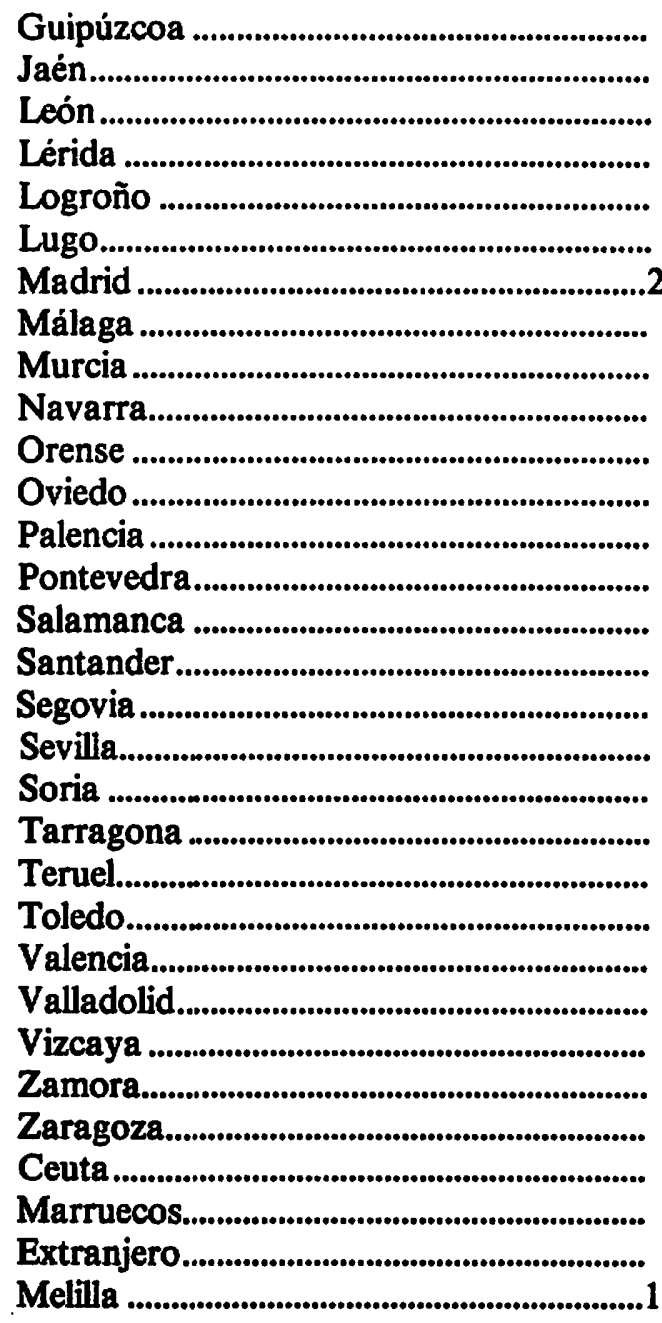

$27.918,00$ pesetas

$1.657,45$ pesetas

135,85 pesetas

862,53 pesetas

0,00 pesetas

461,25 pesetas

287.391,76 pesetas

$24.624,25$ pesetas

$1.000,00$ pesetas

$14.881,53$ pesetas

0,00 pesetas

$5.990,35$ pesetas

$2.356,25$ pesetas

910,35 pesetas

$1.231,57$ pesetas

$6.903,10$ pesetas

30,00 pesetas

376,15 pesetas

1.357,50 pesetas

10,00 pesetas

2.344,10 pesetas

508,10 pesetas

$1.514,65$ pesetas

$1.877,35$ pesetas

21.382,33 pesetas

$1.085,00$ pesetas

$10.912,01$ pesetas

$18.639,15$ pesetas

$99.389,78$ pesetas

21.071,55 pesetas

$117.880,29$ pesetas

TOTAL

$.801 .269,30$ pesetas

El general Primo de Rivera, orientó a la Junta Municipal sobre el modo de invertir el importe de la suscripción prodamnificados, con una carta de su puño y letra. Su idea era construir un nuevo barrio como medida urgente para alojar a las familias que habian quedado sin hogar.

Acompañaba a la carta un esquema y valoración de ajuares para las futuras viviendas, también de su puño y letra. Los melillenses se asombraron de la capacidad de trabajo del ilustre marqués de Estella, pesando sobre él tantos y tan complicados asuntos.

Con respecto al fomento de casas baratas, el 10 de octubre siguiente a la explosión del polvorin, la presidencia de la Junta Municipal presenta una moción al 
pleno de la misma poniendo de manifiesto la iniciativa del general Primo de Rivera para la construción de una barriada de casas ultrabaratas. Esta moción fue aprobada.

Sin pérdida de tiempo se procedió a la construcción de 80 casas, agrupadas en manzanas de a cuatro cada una. Se escogió como lugar de emplazamiento el llano de Alfonso XIII y se pensó en dar al futuro barrio el nombre de Primo de Rivera.

Se convocó un concurso entre los constructores de la localidad y fueron adjudicas las obras al contrastista local señor Perelló en la cantidad de 243.892,20 pesetas, cuya suma fue anticipada por la Comisión de Socorros de las cantidaes recibidas de la suscripcion nacional a favor de las víctimas de la explosión $y$, repuesta, después, por la Junta Municipal, quedando dichas casas de su propiedad.

\section{5.-ACTUACION DE LA JUNTA MUNICIPAL}

El 14 de marzo de 1927, entró en funciones la Junta Municipal de Melilla, creada por Real Decreto de 14 de febrero del mismo, año cesando en su labor la Junta de Arbitrios.

Tarea difícil es condensar la ardua y penosa actuación de la Junta Municipal con motivo de la luctuosa explosión de Cabrerizas Bajas.

Las primeras medidas adoptadas por el presidente accidental de la Junta Municipal, don Francisco de las Cuevas, fueron tan acertadas que antes de finalizar el día 26 de septiembre, habian sido trasladas al depósito del cementerio de la ciudad (Purísima Concepción) los 46 muertos que había producido la explosión (otros dos murieron a consecuencia de las heridas sufridas); quedaban curándose en los hospitales de la Cruz Roja y Pagés los heridos más graves, y en la Casa de Socorro, los más leves. para éstos hubo de instalarse una enfermería en el Laboratorio Municipal.

A consecuencia de la explosión, tuvieron que ser desalojadas por ofrecer peligro o haber quedado destruidas hasta 1.099 casas y barracas. En general, se podía afirmar que fue rara la vivienda melillense que no sufrió algún desperfecto.

Las familias sin albergue buscaron refugio en casas de amigos y parientes, menos 300 familias que la Junta Municipal alojó en los grupos escolares, laboratorio municipal y asilos benéficos. En total 1.200 personas. De su alimentación se encargaron las cantinas escolares.

El mismo día 26 de septiembre, se reunió el pleno de la Junta Municipal y el presidente interino dio cuenta de la catástrofe, alabó los humanitarios sentimientos de los melillenses sin distinción de clases y al ejército, que acudieron solícitos en auxilio de los heridos llevándolos gratuitamente en sus automóviles; curándoles todos los médicos civiles y militares; asistiéndoles los practicantes, damas enfermeras y Hermanas de la Caridad.

El 27 de septiembre, llegan en hidroplano el alto comisario, general Sanjurjo, y 
el presidente efectivo de la Junta Municipal, don Cándido Lobera. Se celebró el entierro de las víctimas, imponente manifiestación de duelo, y quedó constituida la Comisión Permanente de la Junta Municipal en Junta de Socorros, por haber dispuesto el presidente del Consejo de Ministros, general Primo de Rivera, que distribuyese la Corporación el importe de la suscripción que por su iniciativa iba a abrirse en toda España. A este efecto se dividió en las siguientes subcomisiones:

$\left.1 .^{\circ}\right)$ Clasificación de damnificados y de trabajo para los mismos, presidente don Francisco de las Cuevas.

$\left.2^{\circ}\right)$ De asilamiento de los que carecían de albergue, presidente don Angel Carrasco.

3. ) Suscripción y fiestas benéficas, presidente don Francisco Montero.

4. ) Repatriación y donativos en especies, presidente don Ramón Bustos.

$\left.5^{\circ}\right)$ Enterramientos y mausoleo, heridos e incidencias, presidente don Ruperto Prado.

$\left.6^{\circ}\right)$ Cuenta general y especial, presidente don Juan Botella.

7. $\left.{ }^{\circ}\right)$ Barrio Primo de Rivera, presidente don Cándido Lobera.

8.) Correspondencia y suministro de datos, presidente oficial mayor don Pedro Sanabria.

La sección primera, de clasificación de damnificados y trabajo para los mismos tuvo desde el primer día una íntima relación con la Comisión de Socorros a la que tan pronto como se pudo completar el trabajo, se le entregó.

Para adquirir datos que sirvieran de base a la más equitativa clasificación, se dispuso que cierto número de funcionarios visitasen los asilamientos provisionales. Como los datos no eran suficientes, por ausencia de algunos de los damnificados, se citó por la prensa a los que se creyesen perjudicados, pudiendo así completarse la documentación para iniciar de un modo definitivo la clasificación.

Los daños materiales sufridos en cada vivienda y precio de su reconstrucción se cifraron en 1.251 .458 pesetas.

A fin de poder reanudar el curso escolar, el general González Carrasco cedió el antiguo hospital Alfonso XIII para alojamiento de los damnificados. La Comisión de alojamiento, organizó alli dormitorios, escuelas, cocinas y hasta enfermeria y proporcionó trabajo a los hombres y mujeres útiles.

En el mes de diciembre, al no poderse prolongar por más tiempo un estado de cosas que costaba sumas de relativa importancia, se concedió un plazo hasta el 31 de dicho mes para que los asilados buscaran albergue propio, anticipando a cada familia, la cantidad de 200 pesetas.

Las demás comisiones mostraron análoga actividad atendiendo con solicitud a la repatriación, recogida de donativos y expedición de la copiosisima correspondencia recibida en el primer mes.

La Comisión de Socorros celebró 15 sesiones plenarias con un promedio de tres horas por sesión y una serie de reuniones parciales, para la recopilación de datos, clasificación, ayuda, etc., de los darinificados.

Un acuerdo, refleja, el criterio que habia de seguirse:

"Conviene aclarar, en evitación de torcidas interpretaciones, que no se trata 
de fijar indemnización por perjuicios sufridos a consecuencia de la catástrofe, sino de distribuir el producto que de los sentimientos caritativos se obtengan, entre aquellas familias que hayan experimentado desgracias personales o pedido sus modestas viviendas y ajuares cuando era éste todo su patrimonio familiar."

Se formalizaron 1.562 expedientes de los cuales fueron suprimidos 151 , unos anulados por la Comisión, y otros, por renuncias de los interesados a ser socorridos, en beneficio de los demás interesados. Algunos fueron anulados por falsedad de los hechos alegados, también se anularon a quienes los daños sufridos fueron insignificantes.

Después del primer reparto de socorros hecho en marzo, se presentaron algunas reclamaciones. Unas, solicitaban aumento de socorro, otras, pedian ser incluidas como damnificados por no haberlo hecho a su debido tiempo, efecto de ausencia, enfermedad o desconocimiento.

La distribución de socorros se llevó a cabo en sesiones a partir del día 6 de marzo y siguientes hasta el 15 , por tandas, que empezaron los primeros días, de a 50 damnificados, aumentando progresivamente hasta los últimos que se pagaron 200 en cada sesión.

En tres sesiones más celebradas los dias 21 de marzo, 20 y 21 de junio, se abonaron los recibos que habian quedado pendientes, totalizando 1.411 socorros en metálico, por valor de $736.322,98$ pesetas.

Los socorros se asignaron con arreglo a las siguientes clasificaciones:

Primer grupo: familias que tuvieron muertos.

Segundo grupo: familias que tuvieron heridos.

Tercer grupo: inquilinos que tuvieron pérdidas de muebles y enseres.

Algunas familias damnificadas expresaron deseos de volver a la Peninsula y se les facilitó pasaje y un socorro proporcional al número de miembros que la componían. La Compañia Transmediterránea hizo en estos pasajes la bonificación del 50 por ciento.

El número de familias repatriadas alcanzó a 31, elevándose los gastos de repatriación y anticipos, a cuenta del socorro a 3.192,59 pesetas.

La sección de heridos e incidencias se ocupó de facilitar ropas a los que eran dados de alta en los hospitales, pues la mayor parte fueron a ellos envueltos en mantas.

La protección a la infancia se hizo cargo de dos niños que perdieron a sus padres en la catástrofe y la Asociación General de Caridad acogió en sus asilos a varios huérfanos de padre o madre.

Se abrió contabilidad especial para todo lo referente a la catástrofe, dividiendo los gastos en tres grupos:

1.) Los que debia satisfacer de sus fondos la Junta Municipal.

$2^{\circ}$ ) Con cargo a las 50.000 pesetas que ertregó el alto comisario para los primeros auxilios.

3.') Con cargo a la suscripción.

La sección de correspondencia formalizó 346 expedientes referentes a donativos y otro número parecido de informes y contestaciones al pésame que se recibió 
de toda España y del extranjero, lo que es un fiel reflejo de la impresión causada por la catástrofe.

La Asociación General de Caridad, sufragó el importe de las comidas distribuidas en sus locales y la Cruz Roja, las hospitalidades de los encamados en la benemérita institución. Hubo que abonar las del Hospital Militar. Los socorros recogidos fueron entregados a la Asociación General de Caridad.

$\mathrm{La}$ estadística que tenemos de las víctimas de la explosión es la que sigue:

\section{MUERTOS}

Niños: 5

Mujeres: 22

Hombres: 21

\section{HERIDOS}

Atendidos en el Hospital Cruz Roja: 171

Atendidos en el Hospital Militar: 96.

Atendidos en Enfermerias dependientes de la Casa de Socorro: 23.

Hay que añadir el gran número de heridos leves que no quedó reflejado. en cifras concretas.

\section{6.-GRAVE PROBLEMA SOCIAL}

Las memorias de la Asociación General de Caridad, nos muestran cómo esta asociación se ocupó de la inmigración constante de menesterosos, de Levante y sur de España, ofreciéndoles ayuda.

Esta entidad, verdadera Junta de Beneficencia del Municipio, se vio en la necesidad de plantear este problema social, agravado a raíz de la horrenda catástrofe que había sufrido el pueblo de Melilla. Así, en palabras del presidente de la Asociación, don Francisco de las Cuevas: "Los problemas de la miseria que deben compartir equitativamente las ciudades que lo padecen, se acumulan hoy en una como la nuestra, donde precisamente por su situación geográfica y su contacto con pueblos otras razas y otras religiones, que estamos obligados a incorporar a la civilizqción europea, se precisa que se caracterice el nuestro, por una alta ética, una alta moral, una gran capacidad de trabajo, una higiene y una instrucción lo más desarrollada posible; factores todos ellos que se traducen en su reducción al mínimo de dicha miseria.

A todos consta que al amparo de la verdadera necesidad pulula en número desgraciadamente extraordinario otra clase de desventurados cuyo remedio no está precisamente en el ejercicio de estas funciones sagradas, sino por el contrario en una acción coercitiva, dificultándoles el ejercicio de la vagancia para promover un estímulo enérgico y activo que les conduzca por el amor al trabajo a su regeneración y al bienestar de los suyos."

La ciudad de Melilla, gasta en atenciones de beneficencia de un modo directo por las Cajas de la Junta Municipal y de la Asociación General de Caridad más de 
1.000.000 de pesetas al año, y lo triste es que con cifras tan exorbitantes no pueden atender desahogadamente a dichas obligaciones de beneficencia.

El poder ejecutivo se manifestó creando la Comisión que habia de estudiar la inmigración de las plazas de soberania.

A la Sociedad General de Caridad las circunstancias le obligaron a adoptar medidas que fueran precisas para que no se perdiera ni un céntimo de los recursos que ella administraba en fomentar la vagancia, para lo que se propuso que los servicios de los establecimientos benéficos que sostenía sólo se prestaran a las familias realmente necesitadas que hubieran adquirido cartas de naturaleza en la ciudad, haciendo escrupulosamente el padrón de indigentes y colaborando con las autoridades gubernativa y municipal para repatriar a los pueblos de su naturaleza a aquellos que detentaran los recursos destinados a los pobres de Melilla, restableciendo el equilibrio alterado profundamente en la mendicidad melillense. Hay que hacer resaltar que en Melilla estaba prohibida la mendicidad y existian las suficientes organizaciones para que no surgiera.

Tras la catástrofe, como antes hemos indicado, estas organizaciones se hicieron insuficientes y el presidente de la Asociación General de Caridad, don Francisco de las Cuevas, se vio en la necesidad de recordar al Estado español que Melilla era una ciudad especial por su situación geográfica, sus habitantes y sus obligaciones para con ellos, por lo que el Estado no podia considerarla como cualquier otra ciudad española.

"Si a la hora de la guerra, nadie puso en duda que era la nación entera, como así lo hizo con la sangre de sus hijos y los recursos de sus tesoros, la que tuvo que venir aquí a resolver el problema militar que a España le habían planteado de un lado, los compromisos internacionales, y de otro, la indómita rebeldia de las cábilas de nuestro protectorado; a la hora de la paz, no puede dejarse desamparada a esta ciudad por el Estado, ya que las necesidades que en ella se crearon no fueron el fruto de su propia vida, sino que fue una consecuencia lógica e inevitable de la acción nacional en estos territorios, y por tanto, sino todos, muchos de los problemas de Melilla continúan teniendo por derivación el mismo carácter que los originó; carácter nacional claro está."

Existe una necesidad imperiosa de que el Estado se sienta generoso y acuda en auxilio de Melilla.

La Junta Municipal sostiene 128 hospitalidades, de las que Melilla sólo tiene obligación de atender a 68, por ser hijos de la ciudad o llevar más de 10 años en la misma. El resto de los enfermos, deberían ser las Diputaciones de su origen las que abonaran sus gastos.

Melilla, salió adelantı: en este problema social, el Estado no sólo ayudó a la ciudad económicamente, sino que la recompensó por el altruísmo y abnegación de sus habitantes, así lo observamos en el decreto que se publicó en la Gaceta de Madrid el 14 de febrero de 1929: S. M. Alfonso XIII concedió a la corporación municipal de Melilla el tratamiento de "Excelentísima" y el título de "Muy caritativa ciudad". 


\section{7.-EL NUEVO BARRIO PRIMO DE RIVERA}

A partir del año 1921, la población de Melilla había aumentado considerablemente. En los últimos días de diciembre de dicho año, se encontraban empadronadas en Melilla 55.000 personas, ubicada en los siguientes barrios de la ciudad: Reina Regente; Medina Sidonia; Barrio del Carmen; Reina Victoria; Garcia Aldave; Polígono; Principe de Asturias; General Arizón; Industrial; Sanjurjo; Real; Zoco; Gómez Jordana; Alfonso XIII.

El barrio de Reina Regente, que contaba con 10.387 habitantes, fue el más afectado por la catástrofe, ya que en el centro del barrio se encontraban el fuerte y el polvorin que explosionaron.

Este barrio se había formado a espaldas de la Corporación Municipal por la afluencia de emigrantes de la Península que llegaron en masa a la ciudad. El número de edificios que contaba era de 790. La mayoría, viviendas cubiertas de lata y otros materiales poco aconsejables para una buena construcción. Las viviendas se hacinaban en las inmediaciones del fuerte y la Junta Municipal no había descuidado, según parece por ciertas declaraciones, mejoras para este barrio mal construido. Mas, a pesar de todo ocurrió la terrible desgracia antes de que estas viviendas estuvieran en condiciones. Ahora era necesaria realizar la construcción de un nuevo polvorín y, cómo no, de un nuevo barrio.

Se propuso construir un amplio polvorín que sólo sirviera para almacén de pólvora. La nueva edificación se levantó en el interior de una gran barrancada existente en Horcas Coloradas, desenfilada por completo de la ciudad. Constaba de ocho grandes barracones de madera, enguatados de corcho y aislados, por completo, unos de otros. En caso de siniestro, éste no podrá tener otras consecuencias que la destrucción del barracón.

$\mathrm{Al}$ acto de inauguración del nuevo polvorín asistió en nombre de su majestad el Rey, el señor Gómez Jordana, Alto Comisario, sustituto de Sanjurjo.

La construcción del nuevo barrio Primo de Rivera fue todo un éxito. Así, tan sólo en 33 días se consiguió hacer la obra que dejó concluida la nueva barriada.

El 15 de diciembre de 1928, se hizo entrega a los inquilinos futuros de las nuevas ochenta viviendas. Un solemne acto tuvo lugar en la misma barriada presidido por el Alto Comisario, Gómez Jordana, que se encontraba en la ciudad.

El señor Perelló, constructor de la obra, tuvo el magnifico gesto de entregar a cada uno de los nuevos inquilinos además de la llave de su vivienda, un billete de 25 pesetas, obsequio que fue acogido con gran entusiasmo.

Las viviendas estaban formadas por:

Habitación de entrada con amplia ventana; cocina con chimenea y dos dormitorios.

Se construyeron 20 grupos de cuatro casas cada uno, con pilas para lavar y retrete independiente para cada vivienda, además de patio común a las cuatro viviendas de cada grupo.

Todas las habitaciones contenian muebles y un modesto ajuar. La luz, existia 
en el interior de las casas, no en el barrio que se iluminaría con posterioridad.

El agua corriente se llevó a las viviendas desde Yasinen, meses después de la inauguración del barrio, hasta entonces se surtió el barrio del agua que le proporcionó la Comandancia de Artillería.

\section{8.-"HAY QUE SABER SER RICO"}

Con este mismo título, publicó un suelto el diario La Nación estimulando a las personas pudientes para que acudieran a las suscripciones abiertas a beneficio de los damnificados por las catástrofes del Teatro Novedades y del Polvorin de Meli11 a .

Alude concretamente a las familias que disfrutan grandes rentas y recuerda que el verdadero sentido del equilibrio social no puede fundarse en el egoismo de quienes se desentienden de estos deberes.

Comentando este suelto, el popular diario $A B C$ se expresaba en los siguientes términos:

"No tiene disculpa la avaricia de muchos que gozan de privilegiada situación en nuestro país. Sus nombres, jamás aparecen junto a los de millares de personas de posición modesta, que no niegan nunca el concurso de su flaco bolsillo para una obra de caridad.

Podria hacerse una lista de esos acaudalados egoistas, que no saben ser ricos, y la prensa deberia imponerles el correctivo de un tributo indirecto absteniéndose de publicar gratuitamente como hace ahora, las noticias de sus cacerias, de sus banquetes, de sus recepciones y viajes, siempre que no acreditasen el haber contribuido en consonancia con sus medios, al alivio de las desdichas nacionales, y en caso contrario, cobrarles con una alta tarifa la inserción de aquellas noticias, o no publicarlas, destinando el importe a constituir un fondo para remediar las calamidades públicas.

Brindamos la idea a la Unión de Empresas Periodisticas."

Como es lógico este escrito encontró rápida respuesta. El diario La Epoca se ocupó de los sueltos publicados por algunos periódicos como el anterior de $A B C$ contra las clases acomodadas, diciendo que no se puede ejercer la caridad con amenazas.

Este diario se hizo defensor de esta clase social afirmando que las clases altas de la sociedad española practicaban constantemente la caridad sin necesidad de que se les acuciara, así quedaba demostrado en el mantenimiento de una infinita serie de sanatorios, hospitales, refugios, y otros muchos centros por ellos creados.

\section{9.-RECONSTRUCCIONES SIN ARBITRIOS NI PERMISOS}

El comercio, los particulares y propietarios experimentaron graves pérdidas como consecuencia de la catástrofc. Para reconstruir todo, sería necesario solici- 
tarlo a la Junta Municipal, abonar arbitrios y la obligada tramitación burocrática.

Los reglamentos son necesarios para cosas corrientes, lo ocurrido era poco corriente por lo que la Junta autorizó las reconstrucciones sin previa petición, ni abono de impuestos.

El 6 de octubre de 1928 se recibió en la Junta Municipal un telegrama del Presidente del Consejo de Ministros, en el que se comunicaba el acuerdo del Gobierno de la suspensión del aumento del 25 por ciento de contribución industrial para Ceuta y Melilla.

En las circunstancias en que se encontraba Melilla, era un gran alivio, y debía estar muy agradecida a los marqueses de Estella y del Rif, ministro de Hacienda y de modo especial al Director General de Marruecos y Colonias, portavoz de las aspiraciones legitimas de Melilla.

\section{0.-CONCLUSION}

Para el estudio de temas recientes, como el nuestro, el testimonio de las personas que conocieron personalmente los hechos - los "archivos vivos"- es fundamental. Gracias a ellos comprobamos que la actuación general tanto de los organismos oficiales como de la población de Melilla, y España, en general, les merecía la opinión de excelente.

Las ayudas, según ellas, se prestaron con rapidez y eficacia. Se demostró una vez más la solidaridad del pueblo español.

La familia real, el gobierno de la nación, la junta municipal de Melilla, el ejército, los comerciantes, banqueros, asociaciones de caridad y un largo etcétera, aportaron sus servicios desinteresados y sus respectivas economías.

Pero también a estos melillenses les consta que es muy dificil conseguir una perfección absoluta en cualquier realización que el hombre ejecute. Es por lo que testimonian con desánimo como tres provincias españolas no contribuyeron económicamente con un sólo céntimo a sufragar los gastos imprevistos que sufrió la población de Melilla.

A la vez, refieren, se podían haber evitado tantas muertes si no se hubiera permitido jamás la construcción de un barrio en las condiciones en que se formó el de Reina Regente. Y, además la falta de atención en un lugar tan importante como el polvorín; sólo dos hombres lo guarnecian y consideran que no era suficiente.

Un último punto sin resolver es la causa o causas que originaron la explosión. Parece que la ciencia de los años veinte no alcanzaba metas muy altas, las investigaciones dejaron sin cerrar este siniestro. 